DIE DOPPELTE ÄSTHETIK

DER MODERNE 


\title{
Carsten Zelle
}

\section{DIE DOPPELTE ÄSTHETIK DER MODERNE}

\author{
Revisionen des Schönen \\ von Boileau bis Nietzsche
}

Verlag J. B. Metzler Stuttgart $\cdot$ Weimar 
Die Deutsche Bibliothek - CIP-Einheitsaufnahme

Zelle, Carsten:

Die doppelte Ästhetik der Moderne : Revisionen des Schönen von Boileau bis Nietzsche / Carsten Zelle.

- Stuttgart ; Weimar : Metzler, 1995

ISBN 978-3-476-01384-2

ISBN 978-3-476-01384-2

ISBN 978-3-476-03632-2 (eBook)

DOI 10.1007/978-3-476-03632-2

Dieses Werk einschließlich aller seiner Teile ist urheberrechtlich geschützt. Jede Verwertung außerhalb der engen Grenzen des Urheberrechtsgesetzes ist ohne Zustimmung des Verlages unzulässig und strafbar. Das gilt insbesondere für Vervielfältigungen, Übersetzungen, Mikroverfilmungen und die Einspeicherung und Verarbeitung in elektronischen Systemen.

(C) 1995 Springer-Verlag GmbH Deutschland

Ursprünglich erschienen bei J. B. Metzlersche Verlagsbuchhandlung und Carl Ernst Poeschel Verlag GmbH in Stuttgart 1995 


\section{Inhalt}

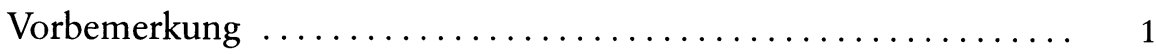

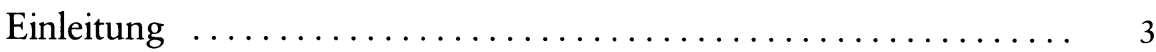

1. Doppelte Ästhetik ............................. 3

2. Der Bruch der Ästhetik mit sich selbst ................. 7

3. Zum Forschungsstand: kallistische Reduktion der Ästhetik Moderne -Querelle - doppelte Ästhetik ................ 11

\section{ERSTER TEIL}

Die Ausbildung des Schemas -

Umwertung durch Supplementierung und Dualisierung 25

I. Sinnmaske des klassizistischen Zeitalters $\ldots \ldots \ldots \ldots \ldots \ldots \ldots \ldots$

1. Umwertung des Klassizismus . .................... 26

2. Ästhetik - Gegendiskurs` zur modernistischen Schönheitslehre .... 30

3. Pathetische Persuasion des Sublimen und die Schönheit der Logik von Port Royal ................................ 36

II. Der Klassizismus und seine Supplemente $\ldots \ldots \ldots \ldots \ldots \ldots \ldots \ldots .43$

1. Erhabenheit und Schönheit - Boileaus Longin-Renaissance ...... 43

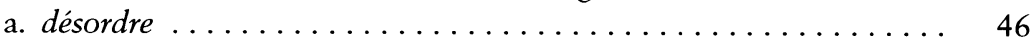

b. sublimité ............................. 49

c. das je ne sais quoi des Erhabenen ................. 57

2. Der andere Klassizismus und seine verborgene Ästhetik - Pascal und Bouhours ................................. 59

a. logique du coeur ............................... 59

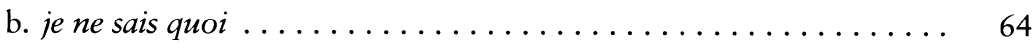

c. Auf dem Weg zu Baumgartens paralogischer Ästhetik ........ 67

III. Entnormierung und Historisierung in der Querelle des Anciens et des Modernes ............................... 74

1. Des Anciens et des Modernes ...................... 76

a. Perraults Le Siècle de Louis le Grand . . . . . . . . . . . . . . . . 77

b. Fontenelles Digression ......................... 79

c. La Bruyères Caractères ......................... 85

2. Ein >doppeltes Maß des Schönen - beau absolu und beau relatif in Perraults Parallele .......................... 87

3. Jenseits des Gegenwartszentrismus - Saint-Évremonds Historismus .. 97

4. Querelle d'Homère - polierte Zivilisation und heroische Sitten ..... 100 


\section{ZweITER TeIL \\ Dualistisches Ordnungssystem und geschichtsphilosophische Kehre 105}

I. Klassischer Antiklassizismus - Horazens Topos des non satis est und dessen strategischer Einsatz . . . . . . . . . . . . . . 105

1. Rückblick auf Boileau und Bouhours . . . . . . . . . . . . 107

2. Fénelons klassische Formel für die halbierte Ästhetik . . . . . . . 108

3. Das Schisma doppelter Ästhetik und der Einschnitt des emotionalistischen Neuansatzes um $1700 \ldots \ldots \ldots \ldots \ldots . \ldots \ldots$

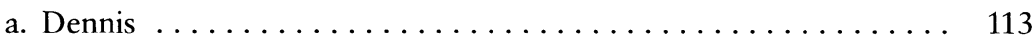

b. Dubos ......................... 118

4. Ausblick auf eine doppelte Schönheit bei Crousaz . . . . . . . . . 120

II. Schönheit und Erhabenheit im 18. Jahrhundert $\ldots \ldots \ldots \ldots \ldots \ldots$

1. Beauty und Sublimity in der englischen Kunsttheorie zwischen Addison und Burke und die Ästhetik des grand gô̂t bei Diderot . . . 124

Exkurs: Kannte Schiller Diderots Salons? . . . . . . . . . . . 128

2. Kallistik und Erhabenheitsästhetik in der deutschsprachigen Literaturund Kunsttheorie vor Kant und Schiller . . . . . . . . . . 131

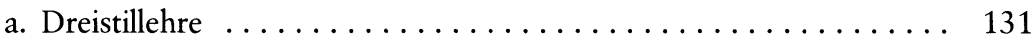

b. Die Leipzig/Zürcher Replik auf die Querelle des Ancien et des Modernes - Schönheit und Erhabenheit in der Longin/BoileauRezeption bei Bodmer/Breitinger, Pyra und Klopstock . . . . . . . .

c. "Das Erhabene verträgt das Schöne nicht" - Kallistik und Erhabenheitsästhetik in der Spätaufklärung . . . . . . . . .

III. Schillers doppelte Ästhetik in seiner Theorie ästhetischer Bildung . . . . . 147

1. Das Erhabene - der blinde Fleck der Klassikdiskussion . . . . . . . 150

2. Kants Dichotomie des Schönen und Erhabenen und Schillers

Duplizität von Anmut und Würde ................

a. Schillers Kant-Rezeption zwischen kallistischer Vermittlung

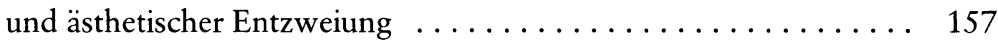

b. Anmut und Würde - die Spannung exzentrischer Anthropologie . . 163

3. Schmelzende und energische Schönheit - die "doppelte Wirkung" von Schillers ästhetischer Erziehung $\ldots \ldots \ldots \ldots \ldots \ldots \ldots$

a. Das Drama menschlicher Exuberanz - Schillers Briefe an den Augustenburger . . . . . . . . . . . . . . . . . .

b. Schönheit, Erhabenheit, Idealschönheit - der Abbruch der ästhetischen Briefe $\ldots \ldots \ldots \ldots \ldots \ldots \ldots \ldots \ldots$

c. Der Preis der Vollendung - klassische Leerformeln bei Karl Morgenstern . . . . . . . . . . . . . . . . . . . . . . . . 177

4. Schillers Aporie - schöne Bildung oder erhabene Freiheit $\ldots \ldots \ldots$. 
DritTER TeIL

Geschichtsphilosophische Ästhetik zwischen nov-antikem Hiat und Dialektik 185

I. Der Antagonismus des Naiven und Sentimentalischen bei Schiller . . . . 188

1. Schillers Mißverhältnis - Vereindeutigungsstrategien

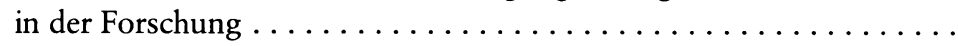

2. Zum Naiven tauglich - transzendentalästhetische Komplementarität .

3. Der doppelte Mangel der Gegenwart - Begriffsdialektik des Naiven,

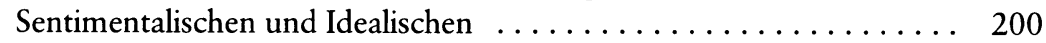

4. Das Sentimentalische ist das Erhabene ... . . . . . . . . 207

II. Objektivität und Interesse in Friedrich Schlegels frühromantischer

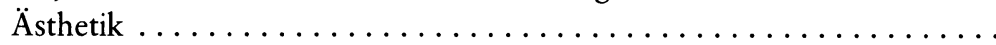

1. De-Sublimation der Geschichte und kallistischer Vorgriff in Schlegels

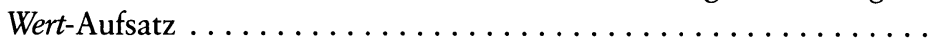

a. Absolute Verschiedenheit und absolute Identität des Antiken und Modernen . . . . . . . . . . . . . . . . . . . . 223

b. Die Verdopplung der Geschichte - Kreislauf und Fortschritt . . . . 230

2. System und Geschichte in Schlegels Bruchstücken zu einer 'modernen Ästhetik` und der Ursprung des Spiels von Allegorie und Ironie . . . . 236

3. Das Objektive und das Interessante - Schlegels Studium-Aufsatz . . . 248

4. Erhabene Schönheit und erhabene Häßlichkeit - das Häßliche als künstlerische Gestaltungsform der Moderne ..............

\section{VIERTER TEIL \\ Ambivalenz des Häßlichen in der Romantik und bei Nietzsche 271}

I. Der Antagonismus zwischen Klassischem und Romantischem

1. Das Pittoreske in August Wilhelm Schlegels Geschichtsphilosophie der Stilqualitäten . . . . . . . . . . . . . . . . . . 272

a. A. W. Schlegels Vorgriffe auf die zweifache Wurzel der Kunst . . . . 272

b. A. W. Schlegels literarisches Schisma - die Antinomien antik/ modern, klassisch/romantisch und plastisch/pittoresk in den Jenaer, Berliner und Wiener Vorlesungen . . . . . . . . . . . . . . . . . 279

c. Ausblick auf "zwei Arten von Schönheit" in Solgers Schlegel-Rezension .

2. Victor Hugos Konfrontation des Schönen mit der Kontrastharmonie des Grotesk-Erhabenen . . . . . . . . . . . . . . . . . . . . . . . . . . . 291

a. Antike und Moderne: le beau und le grotesque . . . . . . . . . . . 294

b. le grotesque und le sublime moderne - das Grotesk-Erhabene . . . . 301 
II. "Es giebt eine doppelte Ästhetik" - Décadence-Kritik und großer Stil beim Apolloniker Nietzsche . . . . . . . . . . . . . . . . . . . . . 304

1. Querelle des Anciens et des Modernes - was Nietzsche

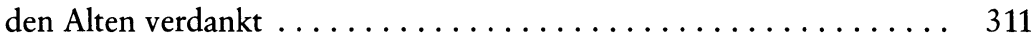

a. Farbloses Hyperhellenentum contra bunte Antike - Nietzsche

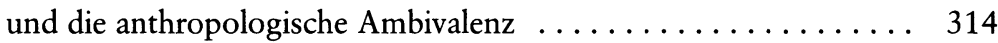

b. Apollinisch-dionysischer Stilgegensatz . . . . . . . . . . . . 319

2. Duplizität des Apollinischen und Dionysischen in der

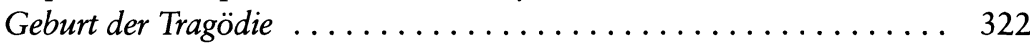

a. Dionysos absconditus - Apollo maskiert Dionysos . . . . . . . . . 324

b. Die Mittelwelt ästhetischen Scheins - "wie Rosen aus dornigem Gebüsch"

c. Versuch einer Selbstkritik - Gegenbewegung zur Ausdifferenzierung der Wertsphären

3. Ästhetik II, zwei Ästhetiken, doppelte Ästhetik - Nietzsches Reformulierung der Wirkungsästhetik zwischen metaphysischem Trost und Stimulans des Lebens . . . . . . . . . . . . . . . . . 338

a. Ästhetik II, zwei Ästhetiken, doppelte Ästhetik . . . . . . . . . . . . . 339

b. "Kraftvermehrung" und "Ermüdung" - die verborgenen Anfänge von Nietzsches Physiologie des Schönen und Häßlichen . . . . . . . 346

4. Décadence und großer Stil . . . . . . . . . . . . . . 349

a. Dionysische und dekadente Häßlichkeit - Nietzsches doppelte Ästhetik des Häßlichen . . . . . . . . . . . . . . . . . . . . . . . . . . . 349

b. Der große Stil - Nietzsches Analysis des Erhabenen .......... 354

\section{Ausblick -Epistemologische Stufe 361}

Literaturverzeichnis . . . . . . . . . . . . . . . . . . . 371

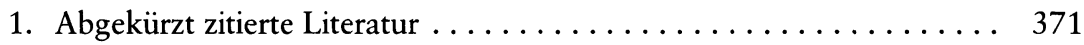

2. Verzeichnis unveröffentlichter Quellen $\ldots \ldots \ldots \ldots \ldots \ldots \ldots \ldots 372$

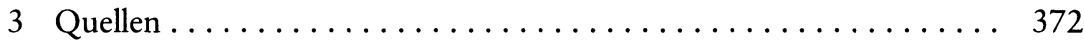

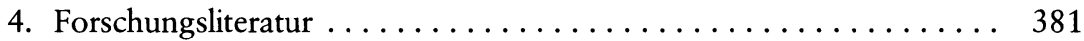

Personenregister ........................... 409 